\title{
Radioactivity in the industrial effluent disposed soil
}

\author{
R. D. SenthilkumaR ${ }^{1, *}$, R. Narayanaswamy ${ }^{2}$ \\ and V. MEENASHISUNDARAM ${ }^{3}$ \\ ${ }^{1}$ Department of Mathematics and Applied Sciences, Middle East College \\ of Information Technology - Oman \\ 2 Department of Physics, Annamalai University - Annamalai Nagar \\ Tamilnadu, India \\ ${ }^{3}$ Department of Atomic Energy, Radiation Safety Section, Indira Gandhi \\ Centre for Atomic Research - Kalpakkam, Tamilnadu, India
}

\begin{abstract}
Studies on radiation and radioactivity distribution in the soils of effluent disposed from the sugar industry in India have been conducted. The external gamma dose rates in air and natural radionuclides activities in the soils were measured using an Environmental Radiation Dosimeter and a Gamma-ray Spectrometer respectively. The soil samples were also subject to various physico-chemical analyses. This study revealed some remarkable results that are discussed in the article.
\end{abstract}

\section{Introduction}

It is well known that India is one of the countries in the world having the highest background radiation levels [1]. Measurement of natural radioactivity in soil is essential to evaluate any change induced by humans in the future and it is also required to trace the movement of radionuclides from the soil reservoir to environmental and biological systems. The primary

*E-mail: senthil@mecit.edu.om

This is an Open Access article distributed under the terms of the Creative Commons Attribution License 2.0, which permits unrestricted use, distribution, and reproduction in any medium, provided the original work is properly cited. 
source of radiation received by human beings is from the natural radioactivity in soils, which derives essentially from ${ }^{40} \mathrm{~K}$ and the radionuclides of the ${ }^{238} \mathrm{U}$ and ${ }^{232} \mathrm{Th}$ decay series. The measurement of ${ }^{40} \mathrm{~K}$ is also useful to agronomists for studies connected with plant nutrients [2].

Sethiyathope is one of the places of Tamilnadu in India, has been identified, from the investigations made by Senthilkumar et al. [3,4], as a polluted area due to the continuous discharge of effluents containing heavy metals with toxic chemicals from the sugar industry. In the present study, an attempt has been made to explore the radiation level and to provide the baseline data for the further assessment of the impact of industrial effluents. Naturally occurring radionuclides, namely, ${ }^{40} \mathrm{~K},{ }^{232} \mathrm{Th}$ and ${ }^{238} \mathrm{U}$, were measured in soil samples of the region, and the resultant dose in air due to these radionuclides was calculated.

\section{Materials and methods}

Twenty-two sampling sites have been selected across the polluted area and soil samples were collected according to standard procedures [5]. They were labelled as $\mathrm{S}_{1}$ to $\mathrm{S}_{22}$. For the physico-chemical analyses, soil samples were processed according to the standard methods $[6,7]$ and the heavy metal concentration was determined using ICP-AES. To find the radioactivity levels, the samples were dried in an oven at $110^{\circ} \mathrm{C}$ till a constant dry weight was obtained. Then these samples were powdered and sieved through a $150-\mu \mathrm{m}$ mesh. The processed soil samples were packed in a $250 \mathrm{ml}$ plastic container to its full volume with uniform mass. These containers were sealed hermetically and also sealed externally to ensure that all the daughter products of uranium and thorium and in particular, radon isotopes formed do not escape. A time of 30 days was allowed after packing to attain secular equilibrium between ${ }^{226} \mathrm{Ra}$ and its short-lived daughter products. The net-weight of each sample was determined before counting. To reduce the contribution from background radiation while recording the spectrum in the laboratory, the samples were kept in a lead shield with a shielding efficiency of 95 percent [8].

The gamma-ray spectrometer was used to determine the activity of the radionuclides, ${ }^{232} \mathrm{Th},{ }^{238} \mathrm{U}$ and ${ }^{40} \mathrm{~K}$. A sodium iodide $[\mathrm{NaI}(\mathrm{Tl})]$ crystal detector of $3^{\prime \prime} \times 3^{\prime \prime}$ size combined with an 8k multi-channel analyser (model PCA-II) was used to record the gamma-ray spectra. Standard International Atomic Energy (IAEA) sources were used for calibrating the gamma-ray spectrometer. The counting time for each sample was 20,000 seconds. 
Table I: Physico-chemical parameters of soil samples.

\begin{tabular}{lrrr}
\hline \multirow{2}{*}{ Parameters } & \multicolumn{2}{c}{ Range } & \multirow{2}{*}{ Mean } \\
\cline { 2 - 3 } $\mathrm{pH}$ & 4.60 & 5.90 & 5.30 \\
$\mathrm{EC}\left(\mathrm{dSm}^{-1}\right)$ & 0.60 & 0.86 & 0.70 \\
$\mathrm{Cd}(\mathrm{ppm})$ & 4.30 & 8.65 & 7.32 \\
$\mathrm{Cu}(\mathrm{ppm})$ & 41.80 & 65.50 & 54.01 \\
$\mathrm{Mn}(\mathrm{ppm})$ & 775.65 & 1215.00 & 1015.30 \\
$\mathrm{Ni}(\mathrm{ppm})$ & 63.12 & 91.00 & 77.57 \\
$\mathrm{~Pb}(\mathrm{ppm})$ & 2.30 & 11.95 & 5.92 \\
$\mathrm{Zn}(\mathrm{ppm})$ & 74.80 & 109.00 & 90.53 \\
$\mathrm{Fe}(\%)$ & 7.90 & 17.70 & 12.46 \\
$\mathrm{Mg}(\%)$ & 1.70 & 3.43 & 2.66 \\
\hline
\end{tabular}

\section{Results and discussions}

\subsection{Physico-chemical analysis of soil}

Table I gives the physico-chemical characteristics of the soil samples. All soil samples were clay in texture. This is due to the continuous disposal of effluents. The absorption pattern of heavy metals, pesticides etc. is higher in clay soil [9]. Soil pH plays a vital role on the availability of nutrient, metal elements, existence of microorganisms and maintenance of physical properties. When electrical conductivity (EC) is more than $1 \mathrm{dSm}^{-1}$, the germination of all crops are affected [10]. The present study shows that the EC values are close to the maximum tolerance limit. The concentration of heavy metals, $\mathrm{Cd}, \mathrm{Cu}, \mathrm{Fe}, \mathrm{Mn}, \mathrm{Mg}, \mathrm{Ni}, \mathrm{Pb}$ and $\mathrm{Zn}$ are also given in table $\mathrm{I}$. $\mathrm{Cd}$ in agricultural soil is mainly due to irrigation with industrial effluents and sewage-sludge in the fields, and it is normally below $1 \mathrm{ppm}[11] . \mathrm{Cu}$ at higher concentration is toxic to most plants and the normal amount in soil is $20 \mathrm{ppm}$ [11]. In this study, a high concentration of $\mathrm{Cu}$ was observed compared to the normal value. Mn, which is an essential element for plants, shows higher concentrations compared to the normal amount of $850 \mathrm{ppm}$. One of the highly toxic metals for plants is $\mathrm{Ni}$. The concentration of $\mathrm{Ni}$ exceeds the recommended amount of $50 \mathrm{ppm}$ for agricultural soils [12]. The concentration of $\mathrm{Pb}$ varied from 2.3 to $11.95 \mathrm{ppm}$. Though $\mathrm{Zn}$ is one of the 
Table II: Activities and exposure dose rates of naturally occurring radionuclides in soil samples.

\begin{tabular}{lrrr}
\hline & \multicolumn{3}{c}{ Range } \\
\cline { 2 - 4 } & Min & Max & Mean \\
\hline${ }^{232}{\mathrm{Th}\left(\mathrm{Bq} \mathrm{kg}^{-1}\right)}^{238} \mathrm{U}\left(\mathrm{Bq} \mathrm{kg}^{-1}\right)$ & 37.3 & 43.2 & 39.75 \\
${ }^{40} \mathrm{~K}\left(\mathrm{~Bq} \mathrm{~kg}^{-1}\right)$ & 20.28 & 24.72 & 22.76 \\
Calculated Dose Rate $\left(\mathrm{nGy} \mathrm{h}^{-1}\right)$ & 220.9 & 270.3 & 253.16 \\
Observed Dose Rate $\left(\mathrm{nGy} \mathrm{h}^{-1}\right)$ & 70.0 & 47.8 & 46.1 \\
\hline
\end{tabular}

essential elements, it is required only in minute amounts. However, higher concentrations of $\mathrm{Zn}$, which varies from 74.8 to $109 \mathrm{ppm}$, were found in this study. As the natural abundance of $\mathrm{Fe}$ and $\mathrm{Mg}$ are more in earth, higher concentrations were noticed.

\subsection{Gamma-ray spectral analysis of soil}

The concentration of primordial radionuclides estimated in the soil samples is presented in table II. The world average concentration of ${ }^{232} \mathrm{Th},{ }^{238} \mathrm{U}$ and ${ }^{40} \mathrm{~K}$ is 30,35 and $400 \mathrm{~Bq} \mathrm{~kg}^{-1}$ [13]. When compared to the activity concentration of radionuclides with the world average value, ${ }^{232} \mathrm{Th}$ is higher by a factor of 1.33 whereas both, ${ }^{238} \mathrm{U}$ and ${ }^{40} \mathrm{~K}$, are lower by a factor of 0.62 .

The external dose rates have been obtained from the soil activity concentration of the three primordial radionuclides. They are given together with the activity concentration of three primordial radionuclides for the soil samples in table II. A graphic plot [fig. 1] of observed dose rate with that of calculated using UNSCEAR [13] conversion factors yielded a good correlation with a co-efficient of 0.89 . Figure 2 shows the frequency distributions of the activities of ${ }^{232} \mathrm{Th},{ }^{238} \mathrm{U}$ and ${ }^{40} \mathrm{~K}$. The activity distributions of ${ }^{232} \mathrm{Th}$ and ${ }^{238} \mathrm{U}$ are practically symmetrical, while the left tail in the activity distribution of ${ }^{40} \mathrm{~K}$ is slightly longer than the right as can be seen in the figs. $2 \mathrm{a}, 2 \mathrm{~b}$ and 2c, respectively. The activities corresponding to ${ }^{232} \mathrm{Th},{ }^{238} \mathrm{U}$ and ${ }^{40} \mathrm{~K}$ are fitted to a normal curve. 


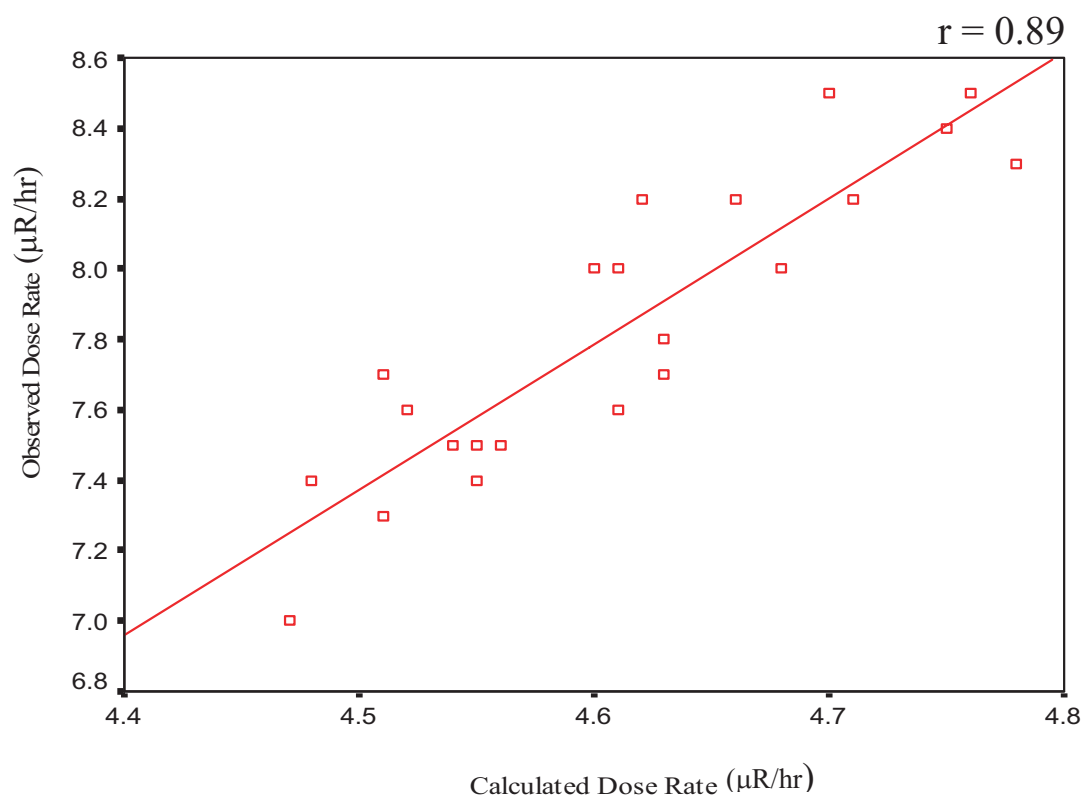

Figure 1: Correlation between calculated and observed dose rates.

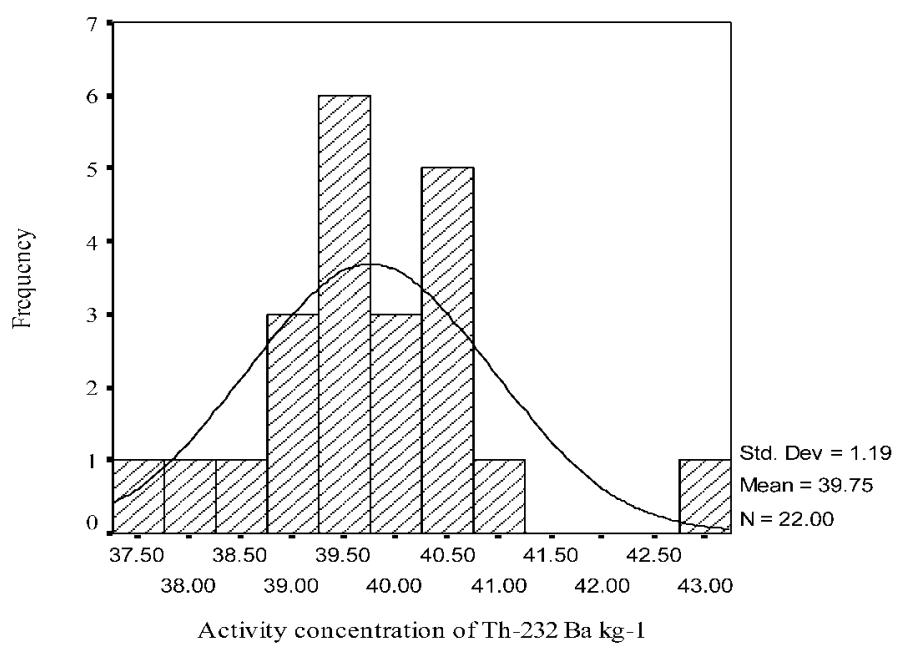

Figure 2a: Frequency distribution of ${ }^{232} \mathrm{Th}$ activities. 
EPJ Web of Conferences



Figure 2b: Frequency distribution of ${ }^{238} \mathrm{U}$ activities.

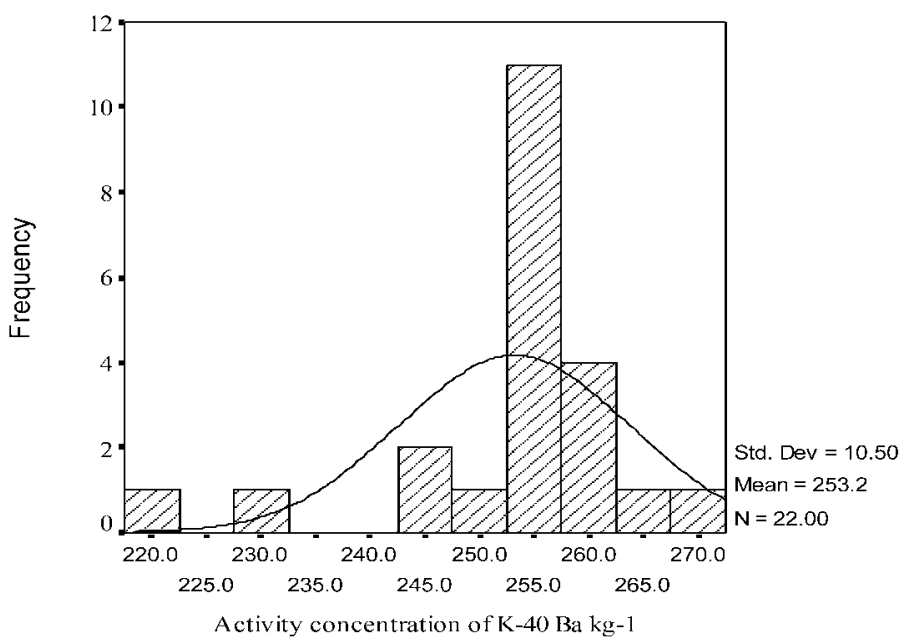

Figure 2c: Frequency distribution of ${ }^{40} \mathrm{~K}$ activities. 
Table III: Gamma does rates from naturally occurring radionuclides.

\begin{tabular}{lcrrr}
\hline & & \multicolumn{3}{c}{ Range } \\
\cline { 3 - 5 } & & Min & Max & Median \\
\hline \multirow{2}{*}{ Dose rate $\left(\mathrm{nGy} \mathrm{h}^{-1}\right)$} & ${ }^{232} \mathrm{Th}$ & 24.84 & 28.77 & 26.41 \\
& ${ }^{238} \mathrm{U}$ & 8.7 & 10.6 & 9.94 \\
Total Dose $\left(\mathrm{nGy} \mathrm{h}^{-1}\right)$ & ${ }^{40} \mathrm{~K}$ & 9.28 & 113.5 & 10.73 \\
& & 45.2 & 48.42 & 46.89 \\
Percentage contribution & ${ }^{232} \mathrm{Th}$ & 53.27 & 60.5 & 56.3 \\
& ${ }^{238} \mathrm{U}$ & 18.71 & 22.38 & 21.15 \\
& ${ }^{40} \mathrm{~K}$ & 20.09 & 24.35 & 22.84 \\
\hline
\end{tabular}

\subsection{Comparison of radioactivities with other environments}

It was found that mean activities of ${ }^{238} \mathrm{U}$ and ${ }^{232} \mathrm{Th}$ were higher by a factor of 1.55 and 2 respectively, when compared to the Indian average values [14]. When compared to the world average values, the activity of ${ }^{232} \mathrm{Th}$ is higher by a factor of 1.33 , while ${ }^{238} \mathrm{U}$ and ${ }^{40} \mathrm{~K}$ are lower in their activities [13].

\subsection{Gamma dose rates from naturally occurring radionuclides}

From the concentration of ${ }^{232} \mathrm{Th},{ }^{238} \mathrm{U}$ and ${ }^{40} \mathrm{~K}$, the gamma dose rates $D$ in air were computed using the procedure reported by Beck et al. [38] and the results are given in table III.

$$
D=0.666 S_{\mathrm{Th}}+0.429 S_{\mathrm{U}}+0.042 S_{\mathrm{K}}\left(\mathrm{nGy} \mathrm{h}^{-1}\right),
$$

where, $S_{\mathrm{Th}}, S_{\mathrm{U}}$, and $S_{\mathrm{K}}$ is the specific activity concentration of ${ }^{232} \mathrm{Th},{ }^{238} \mathrm{U}$ and ${ }^{40} \mathrm{~K}$, respectively.

The gamma dose rate due to the presence of ${ }^{232} \mathrm{Th},{ }^{238} \mathrm{U}$ and ${ }^{40} \mathrm{~K}$ varies from 45.2 to $48.42 \mathrm{nGy} \mathrm{h}^{-1}$ with a median of $46.89 \mathrm{nGy} \mathrm{h}^{-1}$, which is lower than the world average value of $59 \mathrm{nGy} \mathrm{h}^{-1}$. Table III also shows the results of percentage contribution of ${ }^{232} \mathrm{Th},{ }^{238} \mathrm{U}$ and ${ }^{40} \mathrm{~K}$ to the external dose rates in air. The median values of percentage contribution of the dose rates are, respectively, $56.3 \%, 21.5 \%$ and $22.84 \%$. Narayana et al. [15] have reported the percentage contributions to be $46.7 \%$ and $13 \%$, respectively for ${ }^{232} \mathrm{Th}$ and ${ }^{40} \mathrm{~K}$, which are much lower than those of the present study. For Indian 
soils, Mishra and Sadasivam [14] have reported these percentage contributions to be $33.6 \%$ and $48.7 \%$ due to ${ }^{232} \mathrm{Th}$ and ${ }^{40} \mathrm{~K}$, respectively. The world wide average values reported by UNSCEAR [16] for the radioactive contributions to the gamma dose rates in air from ${ }^{232} \mathrm{Th}$ and ${ }^{40} \mathrm{~K}$ are $40 \%$ and $35 \%$, respectively.

\subsection{Correlation between heavy metals and radionuclides}

An attempt has been made to study the correlation between the heavy metals and radioactive elements present in soil samples. A good correlation was observed between the ${ }^{232} \mathrm{Th}$ activity and $\mathrm{Fe}(r=0.76), \mathrm{Mg}(r=0.66)$, $\mathrm{Pb}(r=0.68), \mathrm{Zn}(r=0.68)$ and $\mathrm{Ni}(r=0.68)$. These heavy metals $(\mathrm{Fe}$, $\mathrm{Mg}, \mathrm{Pb}, \mathrm{Ni}$ and $\mathrm{Zn}$ ) are part of the composition of thorium bearing minerals such as Thorlanite, Yttrocrasite, Zirkelite, Brammerire-thorutite series and Polymignite [17]. So this might be one of the reasons that the activity concentration of ${ }^{232} \mathrm{Th}$ is higher than the concentration of ${ }^{238} \mathrm{U}$ in the soil samples.

\section{Conclusion}

Gamma-ray spectral analysis of soil samples reveals the presence of ${ }^{232} \mathrm{Th}$, ${ }^{238} \mathrm{U}$ and ${ }^{40} \mathrm{~K}$ in all the sites of the studied area. The activity concentration of ${ }^{232} \mathrm{Th}$ is higher than ${ }^{238} \mathrm{U}$. A good correlation was observed between ${ }^{232} \mathrm{Th}$ and $\mathrm{Fe}, \mathrm{Mg}, \mathrm{Pb}, \mathrm{Zn}$, and $\mathrm{Ni}$, which are in the composition of thorium bearing elements. The median of the gamma dose rate of $46.89 \mathrm{nGy} \mathrm{h}^{-1}$, is due to the presence of ${ }^{232} \mathrm{Th},{ }^{238} \mathrm{U}$ and ${ }^{40} \mathrm{~K}$. It is lower compared to the world average value. The data obtained in this study will serve as a baseline survey for primordial radionuclide concentration in soil.

\section{Acknowledgement}

The authors would like to express their indebtedness to Dr. A. Natarajan, Former Head, Health and Safety Division and Mr. V. Gajendran, Technician of Gamma-ray laboratory, Indira Gandhi Centre for Atomic Research, Kalpakkam, Tamilnadu, India, for their timely help in carrying out this study. 


\section{References}

[1] Nambi K.S.V., A review of the studies on the high background radiation areas of the world in, III Proceedings of the National Symposium on Environment, Thiruvanandapuram, 1994.

[2] BARC Report, Distribution of Natural Radioactivity and Trace elements in the soils and sands from the high radiation coastal belt of India, Health Physics Division, BARC, Mumbai, 1974.

[3] Senthilkumar R.D., Narayanaswamy R. and SriramachanDRASEKARAn M.V., Journal of Current Science, 2(2) (2002) 123.

[4] Senthilkumar R.D. and Narayanaswamy R., Indian Journal Environmental Protection, 22(7) (2002) 746-749.

[5] Baeza A., Delrio M., Miro C. and Pumiagua J., Journal of Env. Radioactivity, 23 (1992) 19.

[6] PIPer C.S., Soil and Plant Analysis (Hans Publishers, Bombay) 1966.

[7] Alam M.D., Hug S.M.I., Shafique S.M. and Alam K., A Handbook on chemical analyses of soil, plant and water (Dhaka, Bungladesh) 1991.

[8] BeCK H.L., The Natural Radiation Environment - II, USDOE CONF720805-PL (NTIS, Springfield, Virginia) 1972.

[9] RaO J.K., Ecol. Env. \& Cons., 5 (1999) 391.

[10] Sharma B.L., Sharma S., Prasad K. and Srivastava P.N., Indian Journal of Agricultural Chemistry, XXX(1) (1997) 15.

[11] De Han F.A.M. and Zwerman P.J., Pollution of soil in G.H. Bolt and M.G.M. Bruggenwert, eds, Soil Chemistry (Elsevier, Amsterdam) 1976.

[12] Rosales H.L., Carranza E.A. and Lopez H.M., Environmental Geology, 39(3-4) (2000).

[13] United National Scientific Committee on the Effects of Atomic Radiation, Source and effects and risks of ionizing radiation, Report to the General Assembly with annexes (United Nations, NY) 1988. 
[14] Mishra U.C. and Sadasivam S., J. Sci. Industrial Res., 30 (1971) 59.

[15] Narayana Y., Somashekarappa H.M., Karimalara. N., AvadHani D.N. and Mahesh H.M., Health Physics, 80(1) (2001) 25.

[16] United National Scientific Committee on the Effects of Atomic Radiation, Source and effects and risks of ionizing radiation. Report to the General Assembly with annexes (United Nations, NY) 1982.

[17] Durrance E.L., Radioactivity in Geology (Ellis Horwood Ltd., John Wiley and Sons, NY) 1986. 